\title{
Formation of Professional Enhancement of Specialists on the Basis of Pedagogical Technologies
}

\author{
Koishigulova Lyailya ${ }^{1}$, Kabylgazina Klara², Eginissova Almazhai ${ }^{3}$, Utaliyeva Zhanna \\ Tlegenovna ${ }^{4}$ and Omarova Saltanat ${ }^{5}$
}

${ }^{1}$ Atyrau State University H. Dosmuhamedov, Kazakhstan

${ }^{2}$ Kazakh National University, Al Farabi, Almaty, Kazakhstan

${ }^{3}$ Atyrau, Kazakhstan

${ }^{4}$ The Kazakh National University of the Arts, Tauelsizdikst., 50, Astana, 010000, Kazakhstan

${ }^{5}$ Almaty, Kazakhstan

\begin{abstract}
In recent years, in line with the competence-based approach in the domestic and foreign science actively is being developed the problem of formation of professional enhancement "as a mandatory competency component of professional training of modern specialist" in different branches of science - philosophy, sociology, psychology, pedagogy, cultural studies, economics, ethics.

Such a multifaceted study of the phenomenon of "training" is determined by the dynamics of the social life of society, the real needs in the research for modern philosophical orientations is the necessity of its formation in the learning process [1].
\end{abstract}

Keywords: Training, professional, competence, education, science.

\section{INTRODUCTION}

The article considers the conditions for selfrealization of a teacher's personality, the essence and content of the realization of creative potential, which determine the essence of innovative activity and integrated training in the system of vocational education and the need to introduce and use innovations, approbation of new methods for the formation of the teacher's professional competence.

The aim of this research is to discuss formation of professional enhancement of specialists on the basis of pedagogical technologies.

Mentioning that, increasing demands on the quality of professional enhancement of teachers, which must have a high level of training for the successful organization of joint productive activity, effective participation in dialogue on the basis of a competent behavior, active speech, self-regulation and selfcorrection, knowledge and awareness.

Modernization of education requires the teacher to raise his professional level, form and improve the pedagogical culture, corresponding to the demands of modern life.

Address correspondence to this article at the Kazakh State National University of al-Farabi, Almaty, Kazakhstan; Tel: +77073851878;

E-mail: zhanat_2006@mail.ru
Professional competence lies at the basis of the professional development of teachers and is complemented by methodological, social and personal competence. The professional development of teachers is a constant process of updating professional knowledge, skills and abilities. In the current conditions of the development of education - this is the trend of the transition from knowledge to skills and skill, tk. It is necessary to exchange knowledge, transfer them to life, work situations, their transformation, i.e. introduction into practice. In this regard, you can identify the main and additional forms of professional development.

A multidimensional training system should be built on the basis of teacher training. development of knowledge, abilities and skills in the spheres of thinking, motivation, practical application.

Additional forms include: methodical work in institutions, self-development and self-education of the teacher, study, generalization and dissemination of pedagogical experience

For modern education in the whole world, the tendency is to increase the orientation toward the subjective experience of the learner, the development of creativity in combination with the responsibility for the result of their actions. 
A developing society needs modernly educated, moral, enterprising people who are able to take responsible decisions independently in a choice situation, be mobile, dynamic, constructive specialists, and have a developed sense of responsibility for the destiny of the country [2].

To realize this goal, we need not only to update the content and technology of education, but above all, to prepare a teacher who is able to solve these complex social and pedagogical tasks. However, the study of the results of psychological, pedagogical and sociological research.

Formation of professional competence of the future specialist is carried out through the content of education, which includes not only the list of subjects, but also the professional skills and skills that are formed in the process of mastering the subject, and also by means of the student's active position in social, political and cultural life. All this in a complex forms and develops the personality of the future teacher in such a way that she has the methods of self-development and self-improvement that would ensure the teacher effective functioning as a professional subject in the "person-person" system.

The preparation of a competent specialist that meets the requirements of today, endowed with the qualities, knowledge, skills necessary to be specifically capable and viable, is impossible without the construction on a scientific basis of an appropriate training system.

The training of a competent specialist is a process of professional formation of a trainee's personality, conditioned by the high level of professionalism and skill of scientific and pedagogical personnel, innovative technologies in education, and the student's own learning activity, aimed at the formation of professional competence, ability to self-organization and competitiveness.

Presented requirements demand adjustment of the educational process in higher education, to find new ways of professional enhancement, ensuring a high level of formation of the professional training of teachers [3].

In the narrow sense of educational technique is full justification for the choice of professional operational effects on the student teacher in the context of its interaction with the world, in order to form his relationship to the world, harmoniously combines the freedom of personal appearance and socio-cultural norms.

In the scientific literature devoted to the theoretical justification and design of pedagogical techniques, it is possible to find a new understanding.

According to it the pedagogical technique is "not simply researches in the sphere of use of technological tutorials; it researches with the purpose to reveal the principles and to develop methods of optimization of educational process by the analysis of the factors increasing educational efficiency, by designing and application of receptions and materials, and also by means of an assessment of the applied methods [4].

Meanwhile there is no researches in pedagogical and psychological sciences in the area of a comparative analysis of future teachers' professional enhancement based on new technologies in Kazakhstan.

Modern educational practice shows that the level of training, does not fully meet modern requirements of society, employers, as well as the growing needs of the individual itself [5].

Thus, the analysis of the research and the real condition of educational practice leads to the conclusion that there is the necessity of studying the problem of formation of professional enhancement of specialists through innovative technologies and it should be regarded as a targeted process that requires a scientific basis [6].

\section{METHODS}

Survey method was used in the study. The subjects were administered a questionnaire in which they were asked to answer questions related to their profession. Items used in the questionnaire were prepared according to the related literature and interview results conducted with some teachers. Descriptive and inferential analyses were conducted to get a deeper insight into the research questions. Time limit was 90 minutes for the survey.

The reliability and validity of the results of research will be provided the theoretical and methodological bases of initial operating parameters; a collection of scientific techniques that are adequate to the tasks of research and logic; a combination of qualitative and quantitative analysis; statistical significance of the experimental data, their consistency and comparability with the mass of high school practice. 
The research has been carried out at the Faculty of education, Kazakh National Pedagogical University. A total number of 120 students all coming from educational specialties, studying in the BA level to get qualification of the teachers

Most of the students were juniors (67\%), (33\%) were seniors. In terms of the gender, the students were not balanced with 98 Females (82\%), 22 males (18\%) and their age ranged from 17 to 21 .

Table 1: Demographic Background of the Participants

\begin{tabular}{|c|c|}
\hline No. students & 150 \\
\hline Age & $18-21$ \\
\hline Sex & Male: 19 Female: 131 \\
\hline Mother tongue & Kazakh \\
\hline
\end{tabular}

To collect data, the researcher used a questionnaire ranging from 'Strongly Agree' to 'Strongly Disagree'.

The questionnaire had 50 items. The test is reported to have good reliability and validity. Since the participants were all university students the questionnaire was administered in English only. The students were asked to complete the questionnaire in the class after a session. They were also asked to check the questions carefully, read them thoroughly and if there were some questions regarding the understuding of the questions, they were permitted to ask them either in native language (NL) or English target language $(\mathrm{TL})$.

However, it was decided that there are no necessity to represent all of the figures on every item, so the main significant ones are shown in this paper, for researcher with arising interest in the problem of the discussed issue we ask to contact for detailed data.

\section{RESULTS}

As a result of our study, we recorded the following aspects, which require special attention:
Results will be discussed in terms of the distribution of frequencies/percentages and the total means value for each domain given in the example.

The fourth category of TEST items addresses issues about professional learning and communication strategies. Seven items belong to this category; four of them $(27,4$, and 26$)$ concern learning strategies and the others $(12,14,6$ and 21) concern communication strategies. The responses to the items in this category are reported in Table 2.

Actually it is obvious from the table the rates given by the future specialists, so that is why we decided not to represent the analysis. As we mentioned before the most interested researchers can contact us for more details.

\section{DISCUSSION}

The practical significance of the study lies in the fact that the theoretical and experimental study developed problems brought to the level of guidelines, which will successfully be used in the practice of higher education institutions.

Overall, the results of the research is updated the further study of the problem of formation of professional training of specialists.

The purpose of the research is theoretical basis and scientific and methodological support of formation of professional enhancement of teachers through innovative technologies on the basis of comparative analysis.[7]

Taking into account the fact that the current requirements for the training of future teachers, including teachers of a foreign language, has increased, and at the forefront of this process serves high school, the main focus of which should be focused on a comprehensive improvement in the quality of vocational training teaching staff.

Table 2: Survey Result: Professional Learning and Communication Strategies

\begin{tabular}{|c|c|c|c|c|c|}
\hline Item & Source & AG & DA & M & SD \\
\hline 4. it is important to repeat and practice a lot. & KAZNPU & $96 \%$ & -- & 1.34 & 0.63 \\
\hline 12. it is important to speak a foreign language & KAZNPU & $68 \%$ & $18 \%$ & 2.26 & 1.1 \\
\hline 27. I fell self-conscious speaking the professional discourse in front of other people. & KAZNPU & $53 \%$ & $19 \%$ & 2.56 & 0.95 \\
\hline
\end{tabular}

Note: $A G=$ agree, $D A=$ disagree ${ }^{*} K A Z N P U=$ Kazakh National Pedagogical University. The percentages (\%) have been rounded to the nearest tenth 
Training aimed at the formation of a teacher having teaching skills, enhancement of cognitive activity and independence, in turn, requires a professional orientation work among university students in order to develop a deeper interest in the future specialty [8].

Mentioning that, the most important role in the implementation of these requirements is owned educational institutions of higher education, called to carry out the training of the future teacher - teacher, armed with modern scientific knowledge, possessing linguistic theory and practice and knows how to apply the acquired in high school skills into practice.

The results of the surveys (tests, questionnaires, experimentation, etc.), which we conducted showed that students repeatedly pointed at a number of problems on our chosen theme.

The problems faced by the students in the learning process, require high school to review the principles and methods of teaching, bring them in line with the main objective is to teach them practical knowledge [9].

\section{CONCLUSION}

The need for rethinking appears when confronted with a problem-conflict situation, when the previous experience under qualitatively changed conditions is not able to provide positive results in the professional field. This situation can be described as a creative crisis, which includes both positive and negative points. The positive is that the state of the crisis facilitates the search for a new one, but if this can not be achieved, further development of the situation can lead to selfdestruction. As a result of creating a special creative environment, not only the exchange of information and experience on this issue occurs, but also, thanks to the creation of a special atmosphere of co-creation, it is possible to objectify a new meaning, which in future will be the basis of pedagogical activity [10].

Summarizing the conditions of the creative personality of the teacher, it is necessary to emphasize the need to organize learning as a research activity in the context of a significant problem situation, choice of solutions, reaction of ways and personal meaning, and self-awareness as a creative individuality.

In this context, the prospects for the construction of personalized programs, the transition to flexible models of the organization of the educational process, are becoming obvious [11].

\section{REFERENCES}

[1] Message of the President of the Republic of Kazakhstan Leader of the Nation Nursultan Nazarbayev to the people of Kazakhstan Strategy "Kazakhstan - 2050" - new political course of held state. - Astana, 2012, December - 14.

[2] Message of the President of the Republic of Kazakhstan. 2007.

[3] Adam S. Theoretical Poetics. - M., 1990.

[4] Raven D. Competence in modern society: the identification, enhancement and implementation. - M., 1984.

[5] Halazh G. Technology and modern education. - M., 1996.

[6] Hutmaer $V$. Theoretical bases of formation of professional competence of the teacher. - M., 1998.

[7] Andreyev AA. The problem of learning objectives in modern pedagogy. - M., 1989.

[8] Afanasyev AN. Technology and modern education. - M., 1996.

[9] Choshanov MA. Didactic Design of Flexible Technology of Teaching. Pedagogika.- 1997. №2. - P. 21-29.

[10] Pedagogy of professional education: Textbook. allowance for stud. supreme. training. institutions / ed. V.A. Slastenine. Moscow: Publishing Center "Academy", 2008. - 368 p.

[11] Kirichek KA. Comprehensive exam as a form of intermediate certification in the system of ACT. Psychology, Sociology and Pedagogy 2015; 1(40): 86-89.

\section{DOI: https://doi.org/10.6000/2292-2598.2018.06.03.8}

(C) 2018 Lyailya et al.; Licensee Lifescience Global.

This is an open access article licensed under the terms of the Creative Commons Attribution Non-Commercial License (http://creativecommons.org/licenses/by-nc/3.0/) which permits unrestricted, non-commercial use, distribution and reproduction in any medium, provided the work is properly cited. 